\title{
Qualitative syndrome analysis by neuropsychological assessment in preschoolers with attention deficit disorder with hyperactivity
}

\author{
Yulia Solovieva*, Luis Quintanar \\ Autonomous University of Puebla, Mexico, Mexico \\ *Corresponding author. E-mail: yulia.solovieva@correo.buap.mx
}

\begin{abstract}
The basis of this article is A. R. Luria's conception of the qualitative approach in neuropsychology. Attention deficit disorder with hyperactivity is one of the most frequent clinical diagnoses given during preschool age. However, precise qualitative neuropsychological criteria for analysis of this clinical diagnosis do not exist and change from one approach to another. Our objective here is to propose such qualitative criteria for neuropsychological analysis of children with diagnoses of attention deficit disorder with hyperactivity at preschool age. We follow clinical methodology that is traditional for historical and cultural neuropsychology and is an alternative for the psychometrical and cognitive approach. The methodology of the study was qualitative neuropsychological assessment of the syndrome followed by detailed consideration of the types of difficulties in each case. The study analyzes mistakes and typical examples of execution of the tasks of neuropsychological qualitative assessment by regular children and by children with attention deficit disorder with hyperactivity. The results showed differences between these groups of children. The children with attention deficit disorder with hyperactivity made a lot of mistakes during assessments. Their difficulties are related to unfavorable conditions in the three functional brain blocks according to Luria's conception. We conclude that "attention" cannot be considered the only or the main problem in children who receive this diagnosis by psychiatrists and neurologists.
\end{abstract}

Keywords: qualitative neuropsychology, process of attention, disorders of attention, neuropsychological assessment, child neuropsychology

\section{Introduction}

The end of preschool and the beginning of school learning is an important period for cognitive development. According to psychological, neuropsychological, and neurophysiological research, preschool age is a time of significant changes and transformations (Elkonin, 1989; Lisina, 2009; Machinskaya \& Farber, 2014; Vygotsky, 1996). Different developmental disorders can be detected at preschool age, and attention deficit disorder with hyperactivity $(\mathrm{ADDH})$ is among of the most 
frequent of them. In Latin American countries, including Mexico, this diagnosis is so common that even children younger than 3 years old receive it from medical doctors or psychologists. In Mexico, children of all ages with this diagnosis are normally medicated by child neurologists or psychiatrists with methylphenidate (Ritalin). No specific neuropsychological assessment is applied to these children, and no serious psychological help is provided.

Various researchers are trying to study ADDH syndrome in preschool children with the objective of detecting mechanisms and levels of disturbance, including possible effects on different levels of the central nervous system. Compromise of the frontal lobes and diverse alterations of aspects of the processes of attention are commonly claimed (Barkley, 1998, 2001; Castellanos \& Acosto, 2004; Cohen, 1993; Santana, Paiva, \& Lustenberger, 2003).

Nevertheless, in other studies, other processes and not only attention itself are mentioned as being severely impaired in this syndrome. For example, severe problems with space orientation and other aspects of spatial functions in the activities of preschool children have been observed in previous research (Osipova \& Pankratova, 1997; Solovieva, Machinskaya, Quintanar, \& Bonilla, 2007; Solovieva, Machinskaya, Quintanar, Bonilla, \& Pelayo, 2013; Solovieva, Quintanar, \& Bonilla, 2006). It is possible to suppose that not only attention itself and not only frontal lobes are the main problems in ADDH. A direct and unilateral relationship between the process of attention and frontal lobes is not the only point of view in modern neuropsychology and neurophysiology. The participation of complex neuronal systems of cortical and subcortical regulation at different levels is also mentioned by authors who consider the process of attention (Machinskaya \& Farber, 2014; Machinskaya \& Semenova, 2007).

From the point of view of the qualitative clinical approach in neuropsychology, considering complex systems as a basis for the brain's functional representation of psychological process is one of the essential methodological principles (Leontiev, 2009; Luria, 1973/1989, 1977,). According to such principles, psychological processes are considered as psychological actions, each of which is directed to a specific (external or internal) cultural goal. Attention itself is never an independent psychological action. According to Galperin, attention can be understood as an internal action of control (Galperin \& Kabilnitskaya, 1974) that has its own history starting from early childhood. During preschool age, we can speak about attention as an external action of control directed to external goals in joint activity between an adult and a child. It is clear that in such an interpretation attention could never be related to only one type of brain mechanism or to one determinate brain structure. The action of control at the external level will always include different systems of brain mechanisms that are united for the fulfillment of a necessary goal. The absence of goals within the social situation of development produces the absence of actions and, as a consequence, the impossibility of formation of the corresponding cortical and subcortical functional systems.

Historical-cultural neuropsychology, following A.R. Luria’s approach, offers functional analysis of brain mechanisms that might help to determine the clinical features of ADDH syndrome in each particular case. Instead of the traditional psychometrical interpretation of difficulties, qualitative analysis of cortical and subcortical brain mechanisms permits us to characterize the syndrome as a whole 
and not as an isolated quantification of cognitive processes. Such information can be obtained through qualitative analysis of errors and particular features observed during neuropsychological assessment (Akhutina, 1998; Glozman, 2009; Mikadze, 2008; Polonskaya, 2007; Solovieva \& Quintanar, 2006a).

Neuropsychological assessment intends to establish weak and strong functional brain mechanisms of children's activity (Akhutina, 2001). From our point of view, such mechanisms can be understood as psychophysiological elements of functional systems that correspond to actions at the psychological level. For this reason, the use of different methods and levels of analysis might be useful for neuropsychological qualitative assessment.

In particular, in order to evaluate the functional state of brain mechanisms, neuropsychological qualitative analysis frequently includes tasks for evaluation of programming and control, phonemic and kinesthetic integration, sequential motor organization, spatial functions of synthesis and analyses and retention in different modalities, and phonemic cortical nonspecific and emotional activation. In our opinion, these mechanisms cannot have the status of psychological functions or actions. We propose to consider them as elements of functional systems that correspond to children's actions on the psychological level.

The objective of the present study was to share the experience of using qualitative assessment, which permitted us to establish some qualitative criteria for and precise features of the cognitive activity of Mexican preschool children with a diagnosis of ADDH.

\section{Method}

\section{Participants}

The subjects of the study were 16 Mexican preschool children with a diagnosis of ADDH given by a local child psychologist or child neurologist. The diagnosis was established by using the quantitative parameters of DSM-IV (American Psychiatric Association, 2000). The children were selected from regular kindergartens and from Centers of the Attention of Preschool Children with Developmental Disorders in the city of Puebla. The age of all the children was between 5 and 6 years (average age $=5.1$ ). All children had characteristic ADDH problems for periods longer than 6 months. The children presented no other kinds of problems in their psychological development and health.

\section{Neuropsychological assessment}

Neuropsychological assessment was accomplished according to Luria's theory (1973/1989) and its later development in modern child neuropsychology (Akhutina \& Pilayeva, 2012; Mikadze, 2008). Special instruments were developed for Spanish-speaking children between the ages of 5 and 12 (Solovieva \& Quintanar, 2013). The scheme for the Brief Neuropsychological Assessment of Children includes special tasks for assessing brain mechanisms related to Luria’s proposal of three functional blocks: functional block I, which is related to general cognitive and emotional activation and subcortical structures; functional block II, which is related to processing and conservation of information of various modalities and to 
cortical posterior zones; functional block III, which is related to programming and control and to anterior cortical zones (anterior zones).

All tasks were created and adapted with consideration for the cultural and linguistic features of Spanish-language Mexican children and the Spanish language. The tasks were previously tested and applied to groups of normal Mexican populations of preschool children from urban and rural areas.

The objective of our Brief Neuropsychological Assessment was to determine positive or negative functional states of the following neuropsychological mechanisms during the performance of actions:

1) Kinesthetic analysis and synthesis - functional block II

2) Phonemic analysis and synthesis - functional block II

3) Sequential motor organization of actions and movements - functional block III

Table 1. Structure of tasks in the Brief Neuropsychological Assessment of Children (Solovieva and Quintanar, 2013)

\begin{tabular}{|c|c|}
\hline Neuropsychological aspects & Tasks \\
\hline $\begin{array}{l}\text { Kinesthetic analysis and } \\
\text { synthesis }\end{array}$ & $\begin{array}{l}\text { 1. Tactile recognition of common objects. } \\
\text { 2. Repetition of syllables with close articulations. } \\
\text { 3. Poses of fingers. } \\
\text { 4. Reproduction of poses of fingers with closed eyes. }\end{array}$ \\
\hline $\begin{array}{l}\text { Phonemic analysis and } \\
\text { synthesis }\end{array}$ & $\begin{array}{l}\text { 1. Repetition of words with opposite phonemes. } \\
\text { 2. Repetition of syllables with opposite phonemes. } \\
\text { 3. Identification of opposite sounds in series. }\end{array}$ \\
\hline $\begin{array}{l}\text { Sequential motor organiza- } \\
\text { tion of actions and move- } \\
\text { ments }\end{array}$ & $\begin{array}{l}\text { 1. Alternate coordination of hands. } \\
\text { 2. Alternate coordination of fingers. } \\
\text { 3. Copy and continuation of a graphic sequence. }\end{array}$ \\
\hline $\begin{array}{l}\text { Spatial analyses and syn- } \\
\text { thesis }\end{array}$ & $\begin{array}{l}\text { 1. Copy of a house. } \\
\text { 2. Free drawing of a girl and a boy. } \\
\text { 3. Comprehension of complex grammatical structures. }\end{array}$ \\
\hline Visuoverbal retention & $\begin{array}{l}\text { 1. Copy and evocation of five letters. } \\
\text { 2. Copy and evocation of five complex figures. }\end{array}$ \\
\hline Audioverbal retention & $\begin{array}{l}\text { 1. Direct repetition of two series of three words. } \\
\text { 2. Involuntary evocation of two series of three words. } \\
\text { 3. Voluntary evocation of two series of three words. } \\
\text { 4. Retarded evocation of two series of three words. }\end{array}$ \\
\hline Programming and control & $\begin{array}{l}\text { 1. Conflicting verbal instructions presented as a game. } \\
\text { 2. Free game. } \\
\text { 3. Directed game. } \\
\text { 4. Marching by instruction. } \\
\text { 5. Marching by hand signals. } \\
\text { 6. Schulte table (identification of disordered numbers). } \\
\text { 7. Fulfillment of oral instructions. } \\
\text { 8. Identification of smiling faces in a series of smiling, indiffer- } \\
\text { ent, and sad faces. }\end{array}$ \\
\hline $\begin{array}{l}\text { General tonic brain } \\
\text { activation }\end{array}$ & $\begin{array}{l}\text { General observation of the whole procedure of the execution } \\
\text { of all tasks. }\end{array}$ \\
\hline
\end{tabular}


4) Spatial analyses and synthesis - functional block II

5) Visuoverbal retention - functional block II

6) Audioverbal retention - functional block II

7) Programming and control - functional block III

8) General tonic brain activation - functional block I

Special tasks were created in order to observe neuropsychological mechanisms during the execution of a child's actions. Table 1 shows the structure of the tasks of the scheme for the neuropsychological assessment for children.

Qualitative analyses of the types of mistakes made by the children during performance of the tasks and observations of the whole procedure of test application and of the behavior of the children permit us to make claims about the positive or negative functional state of the above-mentioned brain mechanisms. The same task may be significant not only for one but for various functional mechanisms. The objective of qualifying the criteria for errors is finding the relationship between types of errors and features of the positive or negative functioning of each brain mechanism (Solovieva \& Quintanar, 2007).

\section{Procedure}

According to previous agreement with the teachers and parents, all the children were submitted for neuropsychological assessment, which was applied in two or three individual sessions from 40 to 60 minutes in length. Qualitative analysis of the results of the neuropsychological assessment was applied to all cases in order to obtain qualitative clinical syndromes.

\section{Results}

The results of the neuropsychological assessment showed severe deficits not only of the functions that are traditionally related to "attention processes" or to the third functional block established by Luria but also of the mechanisms that are related to all three functional blocks. Among these mechanisms we can mention: programming and control, sequential motor organization of movements and actions, spatial analysis and synthesis, and general brain activation. It is possible to relate these difficulties to the model of three functional blocks proposed by Luria. This relationship is very useful for the unification and concentration of the types of difficulties of children assessed with ADDH syndrome.

Table 2 presents the results of the qualitative analyses obtained by neuropsychological assessment; these results are generalized for all the tested children.

According to the data in Table 2, it is possible to establish the precise relationship between types of errors during execution of the tasks of the neuropsychological assessment and the state of brain mechanisms within one of the functional blocks. The listing in the table of characteristics of execution and type of errors helps in obtaining qualitative parameters of the clinical difficulties of the children.

The general results of the neuropsychological assessment with the help of specific tasks reveal serious difficulties in three aspects of brain functioning: 
Table 2. Concentration of difficulties according to the three functional brain blocks

\begin{tabular}{|c|c|c|c|c|c|}
\hline \multirow{2}{*}{ 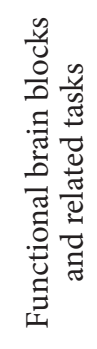 } & \multicolumn{2}{|c|}{$\begin{array}{l}\text { Block I - systems of general } \\
\text { tonic brain activation }\end{array}$} & \multicolumn{2}{|c|}{$\begin{array}{l}\text { Block II — spatial analysis } \\
\text { and synthesis }\end{array}$} & \multirow{2}{*}{$\begin{array}{l}\text { Block III - systems } \\
\text { for programming, re- } \\
\text { gulating, and control- } \\
\text { ling general activity }\end{array}$} \\
\hline & $\begin{array}{l}\text { Task: } \\
\text { Motor coor- } \\
\text { dination of } \\
\text { hands and } \\
\text { fingers }\end{array}$ & $\begin{array}{l}\text { Task: } \\
\text { Copy and } \\
\text { continuation } \\
\text { of a graphic } \\
\text { sequence }\end{array}$ & $\begin{array}{l}\text { Task: } \\
\text { Free drawing } \\
\text { of a boy and } \\
\text { a girl }\end{array}$ & $\begin{array}{l}\text { Task: } \\
\text { Copy of a } \\
\text { model of a } \\
\text { house }\end{array}$ & \\
\hline 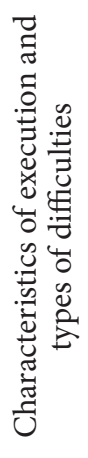 & $\begin{array}{l}\text { Slow ex- } \\
\text { ecution or } \\
\text { impulsive } \\
\text { execution; } \\
\text { fatigue; } \\
\text { constant } \\
\text { distraction }\end{array}$ & $\begin{array}{l}\text { Starting and } \\
\text { leaving the } \\
\text { task; total im- } \\
\text { possibility of } \\
\text { recognizing } \\
\text { the line; lines } \\
\text { and curves } \\
\text { without any } \\
\text { sense; mac- } \\
\text { rography or } \\
\text { micrography }\end{array}$ & $\begin{array}{l}\text { Absence of } \\
\text { both form } \\
\text { and elements; } \\
\text { impossibility } \\
\text { of recogniz- } \\
\text { ing figures } \\
\text { and shapes; } \\
\text { drawings of } \\
\text { a "head with } \\
\text { legs", which is } \\
\text { characteristic } \\
\text { of early child- } \\
\text { hood }\end{array}$ & $\begin{array}{l}\text { Absence of } \\
\text { both form } \\
\text { and elements; } \\
\text { impossibility } \\
\text { of recogniz- } \\
\text { ing figures } \\
\text { and shapes; } \\
\text { "mirror" } \\
\text { mistakes; dis- } \\
\text { integration } \\
\text { of elements; } \\
\text { inversions of } \\
\text { elements }\end{array}$ & $\begin{array}{l}\text { Absence of regulation } \\
\text { by adult's language or } \\
\text { child's own language; } \\
\text { constant motor per- } \\
\text { severations in graphic } \\
\text { tasks; impossibility of } \\
\text { following instructions; } \\
\text { losing of objective; los- } \\
\text { ing of the program of } \\
\text { execution in all motor } \\
\text { tasks }\end{array}$ \\
\hline
\end{tabular}

1) programming and control of activity - functional block III

2) spatial analyses and synthesis - functional block II

3) working functional state of activity -functional block I

In order to understand the specific difficulties of the children, we present examples of models of the tasks, examples of the execution of the tasks by Mexican children of the same age who did not have a diagnosis of $\mathrm{ADDH}$, and examples of execution of same tasks by children with this diagnosis. Figure 1 presents a model of the task of copying and continuing a graphic model.

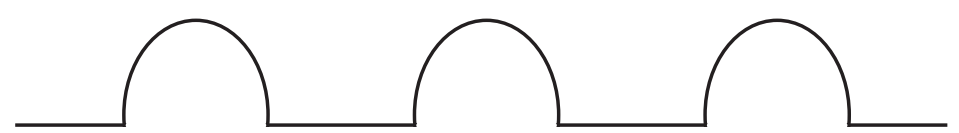

Figure 1. Model of the task of copying and continuing a graphic sequence

Figure 2 presents examples of execution of the task by the preschool Mexican children without ADDH, while Figure 3 shows examples of execution of the task by children with a diagnosis of ADDH.
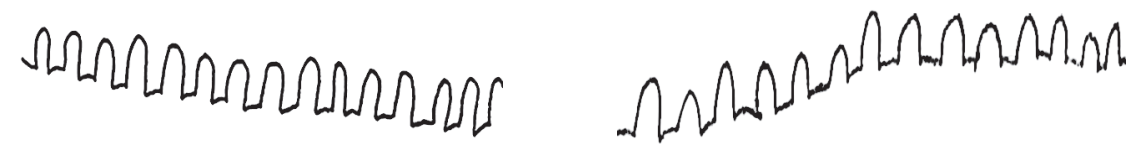

Figure 2. Examples of execution of the task by the control group 


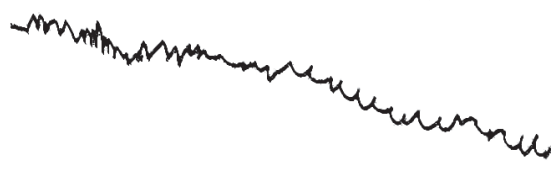

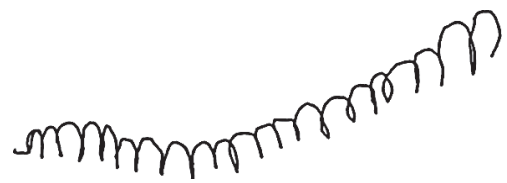

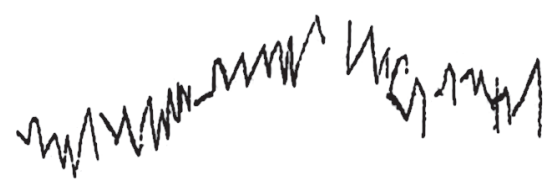

Figure 3. Examples of execution of the task by the group with ADDH

Figure 4 presents the model of the house that the children had to copy during assessment. Figure 5 shows examples of copying of the house by regular children, while Figure 6 presents examples of the same task accomplished by children with a diagnosis of ADDH.

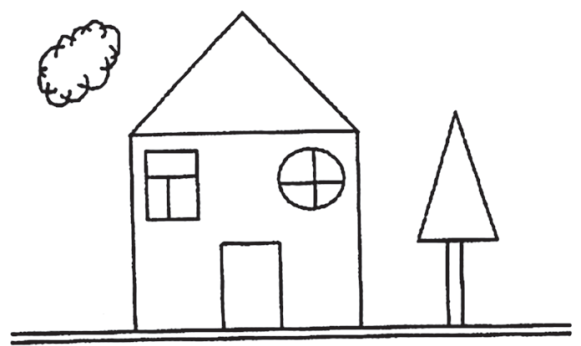

Figure 4. Model of the house for copying
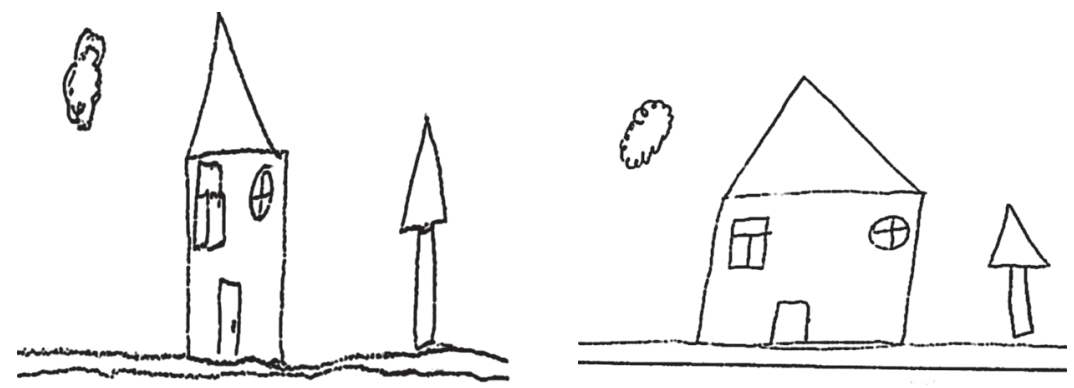

Figure 5. Examples of execution of the task by the control group

Table 3 shows examples of typical execution of three tasks (copying and continuing a graphic sequence, copying a house, and drawing a boy and a girl) by the preschool children with $\mathrm{ADDH}$. In all cases the neuropsychologically dominant difficulties presented by the children were problems with regulation and control, general activation, and spatial integration. These difficulties are related to all three functional blocks of the brain and not to only one of them. These difficulties were severe, as can be observed in the examples. 

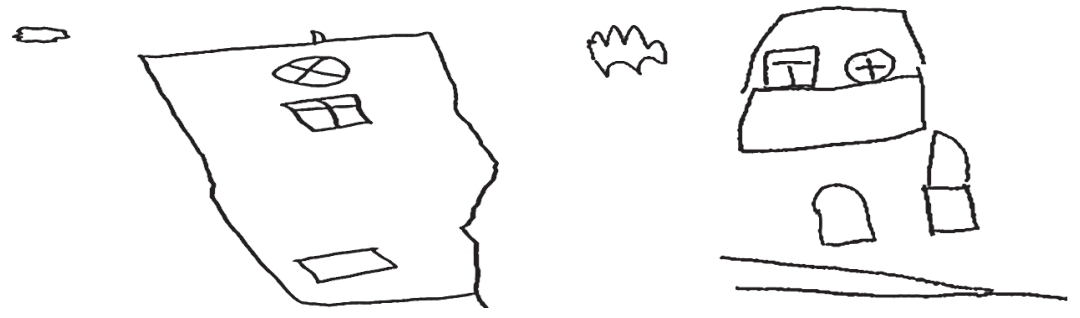

9
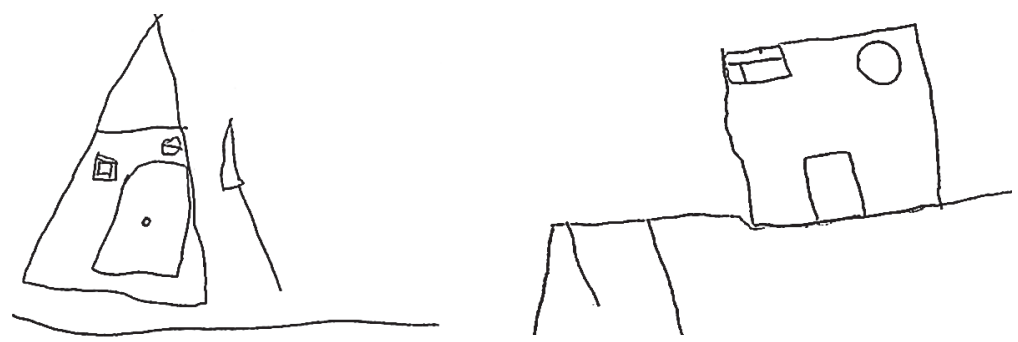

Figure 6. Examples of execution of the task in the group with ADDH

Table 3. Execution of the tasks by children with ADDH

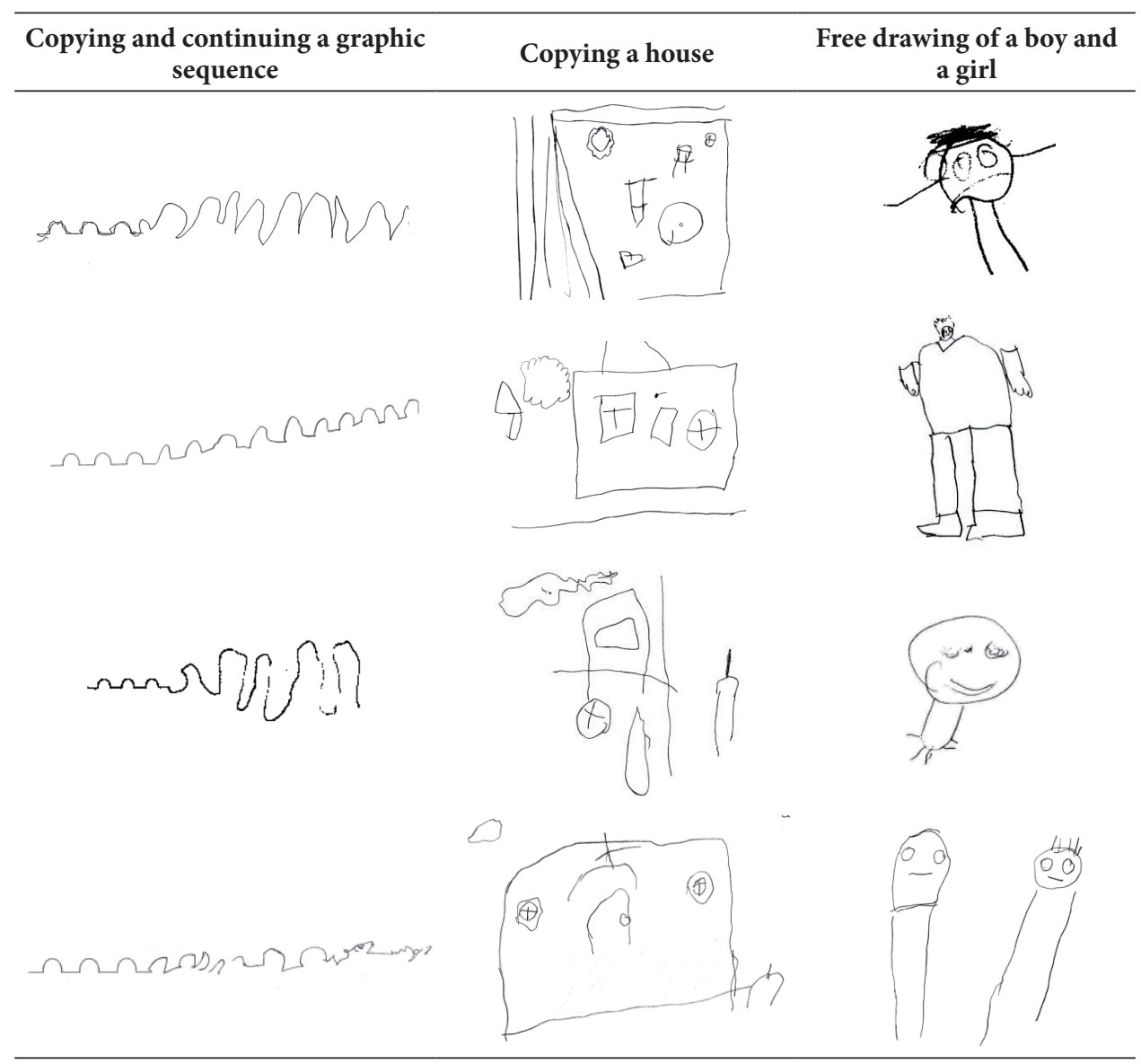




\section{Discussion}

Results of the execution of neuropsychological tasks by the children with ADDH and the children without any disorder can be compared. The results revealed significant differences that favor regular children without ADDH. Children with ADDH showed a neuropsychological profile characterized by severe functional deficits in the programming and control mechanisms, sequential motor organization, spatial analysis and synthesis, and general brain activation. On the basis of these results, we may suppose that ADDH can't be explained by deficit in only one functionfor example, in the function of attention. Our data show that ADDH should be understood only as a complex neuropsychological syndrome in which different mechanisms at different levels of the central nervous system are involved. Various psychological processes and brain mechanisms should be taken into account in order to guarantee adequate interpretation of this clinical picture and for creation of effective methods and strategies for correction.

Diverse signs of types of immaturity were detected in preschool age children in this study. According to our results it is possible to suppose the existence of particular characteristics in these children. Different manifestations of ADDH might be related to particular stages and to unequal functional immaturity at different levels of regulatory brain systems according to specific ontogenetic periods. According to this supposition, the syndrome of ADDH has different manifestations at different ages-for example, at preschool age and in primary school. In preschool children neuropsychological assessment can detect a variety of problems that cannot be subsumed under the term attention deficit. We consider that traditional understandings of the syndrome of "attention deficit disorder" do not reflect the real nature and mechanisms of children's difficulties. The danger is that the methods for overcoming these difficulties are often useless or wrong. Such methods are frequently limited to medication or conductive formal measures, which suppose the executive functions can be trained only by constant repetition or simplification of the tasks. Instead of development, these methods emphasize adaptation to difficulties, which carries the future possibility of personal defects (absence of self-confidence and psychological dependence on medication).

We are convinced that neurological and psychiatric assessments are not substitutes for qualitative neuropsychological evaluation. The objectives of quantitative and qualitative clinical assessments differ in essential ways, and using only a psychometric approach in cases of ADDH in particular and learning and developmental disabilities in general does not fulfill all the requirements of qualitative analysis. In the psychometric approach, attention alone is stressed as the central problem of the syndrome, and all other difficulties are connected to this central problem (Santana et al., 2003). On the contrary, in syndromic analysis within Luria's neuropsychological tradition, weak functional mechanisms are established as a result of analysis of errors according to qualitative criteria. The functional weakness has to be found in each particular case. Afterward, the data from such an analysis may be generalized or systematized according to the goals of the researcher. The situation with the psychometric and cognitive approach is directly the opposite. At the beginning, the researcher claims ADDH and later starts to associate other possible types of difficulties (memory, language, naming, and so on) without any 
apparent connection with the nervous system or with central mechanisms. Such a way of reasoning, in our opinion, cannot lead to understanding the essence of developmental difficulties or to establishment of a clear connection to aspects of the maturation and functioning of the central nervous system.

Our results also show the necessity of including specific methods of correction for the formation not only of strategies for regulation and control but also of spatial functions in the population of children with $\mathrm{ADDH}$ at preschool age (Quintanar, Solovieva, \& Bonilla, 2004; Solovieva, Mata, \& Quintanar, 2014; Solovieva \& Quintanar, 2006b). Only complex programs of directed activity between an adult and a child can guarantee success in the psychological and cognitive development of children with ADDH. Such programs are currently created and applied in our dayto-day practice of neuropsychological correction in Mexico and other countries of Latin America (Solovieva, 2014).

\section{Conclusions}

1. Qualitative analyses of data obtained by neuropsychological assessment of $\mathrm{ADDH}$ syndrome at preschool age revealed a specific complex of difficulties: functional weakness of frontal and posterior associative cortical zones and of general brain activation.

2. Our results show the necessity of including specific methods of correction for formation not only of strategies of regulation and control but also of spatial functions in the population of children with $\mathrm{ADDH}$ at preschool age.

3. We suppose the existence of specific manifestations of functional difficulties with the formation of complex brain systems in different periods of ontogenetic development.

4. The general results of neuropsychological assessment with the help of specific tasks reveal strong difficulties in three aspects of brain functioning:

- programming and control of the child's activity - functional block III

- spatial analyses and synthesis - functional block II

- overall functional state of the child's activity - functional block I

\section{References}

Akhutina, T. V. (1998). The neuropsychology of individual differences in children as a basis for the use of methods of neuropsychological correction in school. In E. D. Khomskaya \& T. V. Akhutina (Eds.), First International Conference Dedicated to the Memory of A. R. Luria (pp. 201-208). Moscow: Moscow State University.

Akhutina, T. V. (2001). Neuropsychological approximation of the diagnosis and correction of learning difficulties in the acquisition of writing. In M. G. Jrakovskaya (Ed.), A modern approach to the diagnosis and correction of speech disorders (pp. 195-213). Saint Petersburg: University of Saint Petersburg.

Akhutina, T. V., \& Pilayeva, N. M. (2012). Overcoming learning disabilities. A Vigotskian-Lurian neuropsychological approach. Cambridge, UK: Cambridge University Press. doi: 10.1017/ CBO9781139012799

American Psychiatric Association (2000). Diagnostic and statistical manual of mental disorders (4th ed., text rev.). Washington, DC. 
Barkley, R. A. (1998). Hyperactivity and attention deficit disorder. Research and Science, 11, 48-53. doi: 10.1038/scientificamerican0998-66

Barkley, R. A. (2001). The executive functions and self-regulation: An evolutionary neuropsychological perspective. Neuropsychological Revue, 11, 1-29. doi: 10.1023/A:1009085417776

Castellanos, F. X., \& Acosta, M. T. (2004). Neuroanatomy of attention deficit disorder with hyperactivity. Journal of Neurology, 38 (suppl. 1), 131-136.

Cohen, R. A. (1993). The neuropsychology of attention. New York: Plenum. doi: 10.1007/978-14419-7463-1

Elkonin, D. B. (1989). Selected psychological works. Moscow: Pedagogy.

Galperin, P. Ya., \& Kabilnitskaya, S. L. (1974). The experimental formation of attention. Moscow: Moscow State University.

Glozman, J. (2009). The neuropsychology of childhood. Moscow: Academia.

Leontiev, A. N. (2009). The psychological bases of the development and teaching of a child. Moscow: Smysl.

Lisina, M. I. (2009). The formation of the personality of a child in communication. Moscow: Piter.

Luria, A. R. (1977). Superior cortical functionas. Havana, Cuba: Orbe. (Original work published 1962)

Luria, A. R. (1989). The brain in action. Mexico: Ediciones Roca. (Original work published 1973).

Machinskaya, R. I., \& Farber, D. A. (2014). Brain mechanisms in the formation of cognitive activity in preschool and minor-school-age children. Moscow: Moscow Psychological and Social University and the Russian Academy of Education.

Machinskaya, R. I., \& Semenova, O. (2007). The role of brain regulatory systems in cortex functional organization and information processing development in primary school children. Psychophysiology, 44 (suppl. 1), 100.

Mikadze, Yu. M. (2008). Child neuropsychology. Moscow: Piter.

Osipova, E. A., \& Pankratova, N. V. (1997). Dynamics of the neuropsychological status of children with different variants of manifestation of the syndrome of attention deficit disorder. School of Health, 4, 34-43.

Polonskaya, N. N. (2007). The neuropsychological diagnosis of minor-school-age children. Moscow: Academia.

Quintanar, L., Solovieva, Yu., \& Bonilla, R. (2006). Analysis of visuospatial activity in preschool children with attention deficit disorder. Human Physiology, 32(1), 43-46. doi: 10.1134/ S0362119706010063

Santana, R., Paiva, H., \& Lustenberger, I. (2003). Attention deficit disorder with hyperactivity. Montevideo, Uruguay: Printer.

Solovieva, Yu. (2014). Intervention in child neuropsychology: Diversity of possibilities. Journal of Neuropsychology of Chile, 9(E2), 46-48.

Solovieva, Yu., Machinskaya, R., Quintanar, L., \& Bonilla, R. (2007). Neuropsychological and electrophysiological correlations in children with attention deficit disorder. Spanish Journal of Neuropsychology, 9(1), 1-15.

Solovieva, Yu., Machinskaya, R., Quintanar, L., Bonilla, R., \& Pelayo, H. (2013). The neuropsychology and electrophysiology of ADDH at preschool age. Puebla: Puebla Autonomous University.

Solovieva, Yu., Mata, A., \& Quintanar, L. (2014). Ways of alternative correction in a case of attention deficit disorder at preschool age. Journal CES Psychology, 7(1), 95-112. 
Solovieva, Yu., \& Quintanar, L. (2006a). Neuropsychological assessment of preschool children with attention deficit disorder: New investigations. Journal of the Academy of Sciences of the Russian Federation, 2(10), 99-108.

Solovieva, Yu., \& Quintanar, L. (2006b). Methods for the neuropsychological correction of Mexican preschool children with attention deficit disorder. Cultural-Historical Psychology, 3, 60-67.

Solovieva, Yu., \& Quintanar, L. (2007). Principles and strategies for the neuropsychological assessment of children. In E. A. Escotto, M. Pérez, \& N. A. Sánchez (Eds.), Linguistics, neuropsychology and the neuroscience of developmental disabilities (pp. 87-101). Mexico City: Autonomous University of Mexico.

Solovieva, Yu., \& Quintanar, L. (2013). Brief Neuropsychological Assessment of Children. Mexico City: Puebla Autonomous University.

Solovieva, Yu., Quintanar, L., \& Bonilla, R. (2004) Neuropsychological correction: An alternative for treatment of children with attention deficit disorder. Spanish Juornal of Neuropsychology, 6(3-4), 171-185.

Vygotsky, S. L. (1996). Selected Works (Vol. 4). Madrid, Spain: Visor.

Original manuscript received May 15, 2015

Revised manuscript accepted August 20, 2015

First published online September 30, 2015 